\title{
Caracterização físico-química das misturas binárias de biodiesel e diesel comercializados no Amazonas
}

\author{
Cristiane Daliassi Ramos de SOUZA ${ }^{1}$, Jamal da Silva CHAAR ${ }^{2}$, Rubem Cesar Rodrigues SOUZA², \\ Manoel Feitosa JEFFREYS ${ }^{4}$, Katiúscia dos Santos de SOUZA5, Everton José Cardoso COSTA ${ }^{6}$, \\ Josana Cória dos SANTOS
}

\begin{abstract}
RESUMO
O uso de energias renováveis aliadas à preservação do meio ambiente tem despertado interesse cada vez maior em nível nacional e internacional principalmente a utilização do biodiesel em substituição ao diesel de petróleo. Sua utilização traz uma série de vantagens sociais, econômicas e ambientais. Nos últimos anos, houve no Brasil um aumento nas pesquisas sobre o biodiesel. A lei brasileira no 11.097 de 2005 dispõe sobre a introdução do biodiesel na matriz energética brasileira, misturado ao óleo diesel em um percentual mínimo obrigatório de 2\%, com aumento na adição para 5\% até 2012. Contudo, essa adição só é possível se o biodiesel estiver dentro dos padrōes de qualidade exigidos. Diante disto, neste trabalho foram preparadas misturas de biodiesel adicionado ao diesel interior, nas proporçôes 2, 5, 10 e $20 \%(\mathrm{v} / \mathrm{v})$, sendo posteriormente caracterizados a partir da determinação dos parâmetros físico-químicos citados na Resolução da Agência Nacional do Petróleo, Gás Natural e Biocombustíveis (ANP), visando avaliar se as misturas estão em conformidade com a norma. De acordo com os resultados concluiu-se que, tanto o biodiesel quanto suas misturas binárias (B2 a B20) encontram-se dentro dos padrões de qualidade estabelecido pela ANP.
\end{abstract}

PaLAVRAS-CHaVE: Biodiesel, Óleo diesel, Parâmetros físico-químicos.

\section{Physical chemical characterization of binary mixtures of biodiesel and diesel commercialized in Amazonas}

\begin{abstract}
The use of renewable energies allied to the preservation of the environment has awakening more and more interest on the national and international level, especially the utilization of biodiesel in substitution of petroleum diesel. Its use brings a series of social, economical and environmental advantages. In the last few years, there has been an increase in biodiesel research in Brazil. The Brasilian law no. 11.097 of 2005 proposes the introduction of biodiesel in the Brazilian energetic matrix, mixing it with diesel oil at an obligatory percentile minimum of $2 \%$, with an increase of $5 \%$ in the addition, until 2012 . However, the addition is only permitted if the biodiesel is within the quality patterns demanded. Before this, mixtures of biodiesel added to interior diesel were prepared, in proportions of 2, 5, 10 and 20\% (v/v), which were later characterized, as of the physical chemical parameters determined in the Agência Nacional do Petróleo, Gás Natural e Biocombustíveis (ANP) Resolution for evaluating mixtures in accordance with the norm. The results show that, biodiesel as well as their binary mixtures (B2 to B20) are within the quality patterns established by the ANP.
\end{abstract}

KEY WORDS: Biodiesel, Diesel oil, Physical chemical parameters.

\footnotetext{
1,2,5,6,7Universidade Federal do Amazonas, Laboratório de pesquisas e Ensaios de Combustíveis (LAPEC).

e-mail: cdaliassi@yahoo.com.br, jchaar@ufam.edu.br, katy_souza@yahoo.com.br, costaejc@bol.com.br, josanacoria@gmail.com

1,3,4Universidade Federal do Amazonas, Centro de Desenvolvimento Energético Amazônico (CDEAM).

e-mail: cdaliassi@yahoo.com.br, rubem_souza@yahoo.com.br, manoel_jeffreys@hotmail.com
} 


\section{INTRODUÇÃO}

O uso de óleos vegetais como combustível tem seu marco inicial ao final do século XIX, quando Rudolf Diesel, inventor do motor a combustão interna, testou em seus motores óleo de amendoim e petróleo bruto (Shay, 1993). Contudo, o petróleo foi preferido como fonte de energia pela sua abundância e baixo preço na época. $\mathrm{O}$ uso de óleos vegetais como combustível ficou então restrito a situaçôes de emergência, como durante as $1^{\text {a }}$ e $2^{\text {a }}$ Guerras Mundiais (Ma \& Hanna, 1999).

Os óleos vegetais são constituídos predominantemente por triacilglicerídeos (três ácidos graxos de cadeia longa ligados na forma de ésteres a uma molécula de glicerol) e como constituintes em menores proporções, os ácidos graxos livres, os mono e di-glicerídeos, além de uma pequena quantidade de outros constituintes não glicerídicos, tais como tocoferóis, carotenóides, esteróis, etc. (Faria et al., 2002).

As proporçôes dos diferentes ácidos graxos saturados e insaturados nos óleos e gorduras vegetais variam de acordo com as plantas das quais foram obtidas, sendo que também dentro de uma espécie existem variações determinadas pelas condiçōes climáticas e tipo do solo em que são cultivados. Os ácidos graxos constituintes dos triacilglicerídeos mais comuns apresentam 12, 14, 16 ou 18 átomos de carbono (Costa Neto et al., 2000).

Nos últimos anos, pesquisas vêm mostrando o acirramento do efeito estufa, em virtude dos altos níveis de gás carbônico emitidos na queima de combustíveis fósseis, provocando mudanças climáticas que afetam toda a população mundial. A preocupação em torno das referidas alteraçōes climáticas e ao alto preço internacional do petróleo é crescente e tem convergido para políticas globais de redução de poluição, onde se vê necessária a transição para uma nova matriz energética (Knothe et. al., 2006.).

Dentro deste contexto, surge o biodiesel, a alternativa mais provável ao petrodiesel. No Brasil inúmeras espécies vegetais podem ser utilizadas para a produção do biodiesel, tais como mamona, soja, algodão, girassol, dendê, etc. (Shahid \& Jamal, 2008; Holanda, 2004). As principais rotas de obtenção dos biocombustíveis a partir destes óleos são a transesterificação e o craqueamento (Demirbas, 2008; Meher et al, 2006; Gerpen, 2005, Alencar et al, 1983).

$\mathrm{Na}$ transesterificação um triacilglicerídeo reage com o álcool na presença de catalisadores dando origem a uma mistura de ésteres de ácidos graxos. O craqueamento consiste na quebra das moléculas por altas temperaturas na presença ou não de catalisadores formando hidrocarbonetos muito semelhantes aos do petróleo, além de compostos oxigenados tais como ésteres, ácidos carboxílicos e aldeídos.
Os ésteres de óleos vegetais, comumente chamados de biodiesel, apresentam propriedades físico-químicas muito semelhantes às do óleo diesel e propiciam uma dinâmica aceitável para o processo de combustão.

O biodiesel apresenta características como: (a) é virtualmente livre de enxofre e aromáticos; (b) tem número de cetano de equivalente a superior com relação ao óleo diesel, (c) possui teor médio de oxigênio em torno de $11 \%$; (d) apresenta caráter não tóxico e biodegradável e (e) possui maior viscosidade, densidade e maior ponto de fulgor que o diesel convencional (Srivastava \& Prasad, 2000; Barreto et al., 2007; Conceição et al., 2005).

A introdução do biodiesel na matriz energética brasileira ocorreu a partir da criação de seu marco regulatório com o Programa Nacional de Produção e Uso de Biodiesel (PNPB) criado por Decreto Lei em 23 de dezembro de 2003 e complementado pela Lei ${ }^{\circ} 11.097$ de 13 de janeiro de 2005.

A Agência Nacional do Petróleo, Gás Natural e Biocombustíveis (ANP) é o órgão regulamentador de derivados de petróleo e combustíveis no Brasil e determinou que no período de 2005 a 2007 o biodiesel fosse utilizado de forma facultativa misturado ao óleo diesel mineral na proporção máxima de $2 \%$ de biodiesel para $98 \%$ de diesel, formando o chamado combustível B2. Sua adição ao óleo diesel nesta proporção passou a ser obrigatória em janeiro de 2008. Contudo, a Resolução 02/2008 do Conselho Nacional de Política Energética (CNPE) tornou obrigatório o uso do combustível B3, ou seja, com a adição de $3 \%$ de biodiesel ao diesel a partir de $1^{\circ}$ de julho de 2008 (CNPE, 2008).

A partir de 2013, esta proporção aumentará para $5 \%$ de biodiesel no diesel (B5), com perspectives de crescimento deste percentual para os anos seguintes. Desta forma, existe hoje uma preocupação em controlar a qualidade do biodiesel, devido seu processo natural de degradação, corrosão ou adulteração, e consequentemente as suas misturas ao diesel.

Desta forma, este trabalho apresenta como objetivos a avaliação da qualidade dos combustíveis, biodiesel e diesel interior, comercializados na cidade de Manaus-AM, assim como verificar a compatibilidade química dos resultados obtidos nas análises físico-químicas das misturas de biodiesel e diesel, em diferentes proporçôes volumétricas, com os parâmetros exigidos pela ANP, que estabelece especificaçóes para a comercialização do biodiesel, do óleo diesel e das misturas automotivas, definindo as obrigações sobre o controle de qualidade dos produtos em território nacional. 


\section{MATERIAL E MÉTODOS}

\section{PREPARAÇÃO DAS AMOSTRAS}

Foi utilizada uma amostra de biodiesel, obtido pelo processo de transesterificação do óleo de soja, gentilmente cedida por uma empresa privada do setor de combustíveis, e o diesel automotivo interior (ou diesel tipo "B"), coletado em um ponto de revenda de combustível na cidade de ManausAM.

Foram preparadas misturas volumétricas (v/v), sob agitação constante, à temperatura ambiente, para serem avaliadas nas concentraçôes de $2 \%, 5 \%, 10 \%$ e $20 \%$ de biodiesel com o diesel, o que corresponde às misturas B2, B5, B10 e B20, além do diesel e biodiesel puro, denominado B0 e B100, respectivamente.

\section{ANÁLISES FÍSICO-QUIIMICAS}

As amostras de biodiesel e diesel interior comerciais foram analisadas para verificação de suas conformidades segundo a ANP (ANP, 2004; ANP, 2006).

As características físico-químicas avaliadas para o biodiesel, o diesel interior e as misturas foram: Aspecto, Massa Específica à $20^{\circ} \mathrm{C}$ (densímetro automático DMA 4500), Viscosidade Cinemática à $40{ }^{\circ} \mathrm{C}$ (viscosímetro SCHOTT - GERATE), Teor de Enxofre (EDX 700 - SHIMADZU), Índice de Acidez (Esteves et al, 1995), Destilação (Destilador Manual - HDA 620 - HERZOG), Ponto de Fulgor (Pensky Martens Automático - HERZOG).

O Índice de Cetano (IC) é um método alternativo para predição do Número de Cetano (NC) do combustível (mede a qualidade de ignição do combustível que afeta a partida e a aceleração do motor) aprovado pela ASTM e ABNT. O IC não utiliza o motor CFR, mas uma equação de correlação baseada nas propriedades físicas do combustível determinadas (densidade e temperatura de destilação do produto). Foi calculado o IC para todas as misturas binárias em estudo (ANP, 2006).

Foram realizados também testes de calorimetria em todas as amostras através de um calorímetro PARR modelo 1341, pelo qual foi determinado o Poder Calorífico Superior (PCS) utilizando o método da bomba calorimétrica.

O estudo do potencial energético do biodiesel e das suas misturas foi realizado mediante o emprego das normas da American Society of Testing and Materials (ASTM) e Associação Brasileira de Normas Técnicas (ABNT), indicadas pela Resolução 15/2006 da ANP, que especificam valores para as propriedades e características do óleo diesel e das misturas de biodiesel e diesel, assim como os respectivos métodos para suas determinações (ANP, 2006).

\section{RESULTADOS E DISCUSSÃO}

Os parâmetros físico-químicos para o biodiesel puro (B100) foram determinados conforme a Resolução ANP 42/2004 no sentido de avaliar sua concordância com esta especificação, sendo apresentados na Tabela 1. Os resultados obtidos nos ensaios indicam que o B100 utilizado neste trabalho encontra-se dentro dos limites permitidos pela respectiva Resolução (ANP, 2004).

\begin{tabular}{|c|c|c|c|}
\hline Ensaios & Método & Limite & B100 \\
\hline Aspecto & VISUAL & LII & LII \\
\hline $\begin{array}{l}\text { Massa específica a } 20 / 4{ }^{\circ} \mathrm{C} \\
\left(\mathrm{kg} / \mathrm{m}^{3}\right)\end{array}$ & ASTM D 4052 & anotar & 882,0 \\
\hline $\begin{array}{l}\text { Viscosidade Cinemática a } 40^{\circ} \mathrm{C} \\
\left(\mathrm{mm}^{2} / \mathrm{s}\right)\end{array}$ & $\begin{array}{l}\text { ASTM D } 445 \text { / NBR } \\
10441\end{array}$ & anotar & 4,32 \\
\hline Ponto de fulgor $\left({ }^{\circ} \mathrm{C}\right)$ & $\begin{array}{l}\text { ASTM D } 93 \text { / NBR } \\
14598\end{array}$ & mín. 100 & 175 \\
\hline Índice de acidez (mg KOH/g) & ASTM D 664 & 0,8 & 0,8 \\
\hline Teor de enxofre total $(\% \mathrm{~m} / \mathrm{m})$ & ASTM D4294 & anotar & 0,000 \\
\hline PCS* (MJ/kg) & $\begin{array}{l}\text { Bomba } \\
\text { calorimétrica }\end{array}$ & - & 42,61 \\
\hline
\end{tabular}

LII = Límpido e Isento de Impurezas

PCS = Poder Calorífico Superior

* Base Seca

Quanto aos resultados das análises de qualidade da adição do biodiesel no diesel interior, mediante elevação do percentual volumétrico de biodiesel na mistura estão listados na Tabela 2. Também é apresentada uma comparação com as características do óleo diesel puro (B0) e com os limites estabelecidos pela Resolução ANP 15/2006 (ANP, 2006).

Foi observado também que o aumento da proporção de biodiesel na mistura binária promove uma elevação na Massa Específica, isto ocorre devido às interaçōes moleculares, visto que o óleo diesel tem na sua composição somente hidrocarbonetos, enquanto que o biodiesel é formado por ésteres. Valores altos de Massa Específica possibilitam um bom funcionamento do motor, com boa lubrificação, evitando entupimentos.

A Viscosidade Cinemática, que também é uma propriedade fluidodinâmica, expressa a resistência oferecida pela substância ao escoamento sob gravidade. Os resultados do efeito da adição do biodiesel no óleo diesel referente a esta propriedade podem ser observados na Tabela 2. Os valores expressam um aumento da viscosidade com a adição do biodiesel. Este resultado é esperado uma vez que o biocombustível possui uma viscosidade mais elevada que o óleo diesel. O controle deste parâmetro de qualidade visa garantir um funcionamento adequado nos sistemas de injeção e nas bombas de combustível. 
Tabela 2 - Comparação das características físico-químicas do diesel puro (B0) e das misturas de biodiesel e diesel

\begin{tabular}{|c|c|c|c|c|c|c|c|}
\hline \multirow{2}{*}{ Propriedades } & \multirow{2}{*}{ Método } & \multirow{2}{*}{ Limite } & \multicolumn{5}{|c|}{ Amostras } \\
\hline & & & B0 & B2 & B5 & B10 & B20 \\
\hline Aspecto & VISUAL & LII & LII & LII & LII & LII & LII \\
\hline $\begin{array}{l}\text { Massa específica a } 20{ }^{\circ} \mathrm{C} \\
\left(\mathrm{kg} / \mathrm{m}^{3}\right)\end{array}$ & $\begin{array}{l}\text { ASTM } \\
\text { D } 4052\end{array}$ & $820-880$ & 838,5 & 839,3 & 841,3 & 844,1 & 850,6 \\
\hline $\begin{array}{l}\text { Viscosidade Cinemática a } 40{ }^{\circ} \mathrm{C} \\
\left(\mathrm{mm}^{2} / \mathrm{s}\right)\end{array}$ & $\begin{array}{l}\text { ASTM D } 445 \\
\text { NBR } 10441\end{array}$ & $2,0-5,0$ & 3,50 & 3,47 & 3,53 & 3,55 & 3,61 \\
\hline Ponto de Fulgor $\left({ }^{\circ} \mathrm{C}\right)$ & $\begin{array}{l}\text { ASTM D } 56 \\
\text { NBR } 7974\end{array}$ & mín. 38,0 & 71 & 71 & 72 & 73 & 76 \\
\hline $\begin{array}{l}\text { Índice de Acidez } \\
(\mathrm{mg} \mathrm{KOH} / \mathrm{g})\end{array}$ & $\begin{array}{l}\text { ASTM } \\
\text { D } 664\end{array}$ & máx. 0,8 & 0,53 & 0,55 & 0,61 & 0,69 & 0,79 \\
\hline Teor de Enxofre Total (\% m/m) & $\begin{array}{l}\text { ASTM D } 1552 \\
\text { NBR } 14875\end{array}$ & máx. 0,2 & 0,134 & 0,120 & 0,111 & 0,105 & 0,095 \\
\hline $\begin{array}{l}\text { Destilação } \\
50 \% \text { recup. }\left({ }^{\circ} \mathrm{C}\right) \\
85 \% \text { recup. }\left({ }^{\circ} \mathrm{C}\right)\end{array}$ & $\begin{array}{l}\text { ASTM D } 86 \\
\text { NBR } 9619\end{array}$ & $\begin{array}{l}245 \text { a } 310 \\
\text { máx. } 370\end{array}$ & $\begin{array}{l}270 \\
331\end{array}$ & $\begin{array}{l}273 \\
332\end{array}$ & $\begin{array}{l}276 \\
334\end{array}$ & $\begin{array}{l}280 \\
335\end{array}$ & $\begin{array}{l}292 \\
336\end{array}$ \\
\hline Índice de Cetano & $\begin{array}{l}\text { ASTM D } 976 \\
\text { NBR } 14759\end{array}$ & mín. 45 & 45,7 & 50,8 & 50,7 & 50,6 & 50,7 \\
\hline $\mathrm{PCS}^{*}(\mathrm{MJ} / \mathrm{kg})$ & $\begin{array}{l}\text { Bomba } \\
\text { calorimétrica }\end{array}$ & - & 50,99 & 49,21 & 48,54 & 47,50 & 46,16 \\
\hline
\end{tabular}

LII = Límpido e Isento de Impurezas

PCS $=$ Poder Calorífico Superior

* Base Seca

Da mesma forma, foi constatado um aumento no Ponto de Fulgor (ou ponto de ignição), ficando bem acima do mínimo especificado na norma. Este parâmetro indica a temperatura mínima na qual o combustível forma com o ar uma mistura inflamável, sendo de grande importância para a segurança no transporte, manuseio e armazenamento.

Quanto à análise do Teor de Enxofre foi observada uma redução com o aumento da quantidade de biodiesel na mistura binária, enfatizando sua eficiência ambiental, traduzindo em menores níveis de emissão de $\mathrm{SO}_{\mathrm{x}}$ para a atmosfera. Vale ressaltar que a redução do Teor de Enxofre proporcionada pela adição de biodiesel no diesel interior pode resultar em uma mistura de combustível de uso metropolitano.

Os valores do Índice de Acidez de todas as misturas ficaram dentro do limite permitido pela ANP. Um índice de acidez elevado influencia na hidrólise do biodiesel e na sua oxidação, e pode catalisar reaçôes intermoleculares dos triacilglicerídeos, ao mesmo tempo em que afeta a estabilidade térmica do combustível na câmara de combustão. Além disso, no caso do emprego carburante do óleo, a elevada acidez livre tem ação corrosiva sobre os componentes metálicos do motor.

As temperaturas monitoradas no ensaio de Destilação, segundo a Resolução 15/2006 da ANP, são as correspondentes a $50 \%$ e $85 \%$ do volume recuperado. Foi observado que um teor de até $20 \% \mathrm{v} / \mathrm{v}$ de biodiesel no diesel interior não torna a amostra não conforme nestes dois parâmetros. Entretanto a temperatura aumenta gradativamente, indicando que a partir do B20 pode ocorrer não conformidade.

Quanto à qualidade de ignição dos combustíveis, determinada através do Índice de Cetano (IC), foi observado um aumento quando o biodiesel é adicionado ao diesel interior. Valores altos do IC facilitam a partida a frio e um aquecimento mais rápido do motor, assim como, reduz a possibilidade de erosão dos pistões e minimiza a emissão de poluentes como hidrocarbonetos, monóxido de carbono e material particulado.

A análise calorimétrica foi realizada mediante o ensaio do Poder Calorífico Superior (PCS), o qual mede o poder carburante do combustível através da determinação da potência máxima a ser atingida pelo motor em operação. $\mathrm{O}$ PCS foi determinado para todas as amostras apresentando uma pequena redução, mas com valores muito próximos ao do diesel interior.

\section{CONCLUSÃO}

A utilização de misturas de biodiesel ao diesel como combustível tem apresentado um potencial promissor no mundo inteiro, devido a sua enorme contribuição ao meio ambiente, com a redução dos níveis de poluição ambiental, assim como nova fonte de energia renovável em substituição ao diesel puro e outros derivados do petróleo. 
De acordo com os resultados da caracterização físicoquímica, a adição de biodiesel ao diesel interior apresentou conformidade com a especificação da ANP para todos os parâmetros estudados neste trabalho. Desta forma, concluise que, o biodiesel e suas misturas com o diesel interior, comercializados na cidade de Manaus-AM, encontram-se dentro dos padrôes de qualidade, nas faixas de concentrações analisadas. Entretanto, devem ser intensificados os estudos de identificação e quantificação do percentual de biodiesel no diesel, que hoje deve ser de 3\% (B3), e que já devem estar sendo utilizados nos postos de combustíveis em todo o país.

\section{AGRADEC IMENTOS}

Os autores agradecem ao Laboratório de Pesquisas e Ensaios de Combustíveis (LAPEC), ao Laboratório de Análises Físico-Química do Centro de Desenvolvimento Energético Amazônico (LAFQ-CDEAM), localizado na Fazenda Experimental, ambos da UFAM pelas análises realizadas, e ao Conselho Nacional de Desenvolvimento Científico e Tecnológico (CNPq) pelo incentivo financeiro.

\section{BIBLIOGRAFIA CITADA}

Alencar, J.W.; Alves, P.B.; Craveiro, A.A. 1983. Pyrolysis of tropical vegetable oils. Journal of Agricultural and Food Chemistry, 31: 1268-1270.

ANP - Agência Nacional do Petróleo. 2004. Resoluçāo ANP 42/2004. Disponível em www.anp.gov.br/petro/legis_qualidade.asp. Acesso em 09 de janeiro de 2008.

ANP - Agência Nacional do Petróleo. 2006. Resolução ANP 15/2006. Disponível www.anp.gov.br/petro/legis_qualidade.asp. Acesso em 09 de janeiro de 2008.

Barreto, A.J.B.; Mendes, D.; Junior, J.A.F.; Souza, J.; Coimbra, M.D.J. 2007. Estudo da adição de biodiesel do óleo de palma no óleo diesel. Disponível em www.biodiesel.gov.br/docs/ congresso2007. Acesso em 03/03/2008.

CNPE - Conselho Nacional de Política Energética. 2008. Resolução CNPE 02/2008. Disponível em www.mme.gov.br/site/menu. Acesso em 13/10/08.
Conceição, M.M.; Candeia, R.A.; Dantas, H.J.; Soledade, L.E.B.; Fernandes Jr., V.J.; Souza, A.G. 2005. Rheological behavior of castor oil biodiesel. Energy \& Fuels. 19: 2185-2188.

Costa Neto, P.R.; Rossi, L.F.S.; Zagonel, G.F.; Ramos, L.P. 2000. Produção de biocombustível alternativo ao óleo diesel através da transesterificação de óleo de soja usado em frituras. Química Nova, 23(4): 531-537.

Demirbas, A. 2008. Progress and recent trends in biodiesel fuels, Energy Conversion and Management, in press. Disponível em www.sciencedirect.com. Acesso em 10/06/08.

Esteves, W.; Gonçalves, L.A.G.; Barrera-Arellano, D. 1995. Metodologia padrão alemã para análise de gordura e outros lipídeos (Tradução de: Deutsche Einheitsmethodem zur Untersuchung von Fetten, Fettprodukten, Tensiden und verwandten Stoffen Abteilung A, B, C, F). Campinas, 325pp.

Faria, E.A.; Leles, M.I.G.; Ionashiro, M.; Zuppa, T.O.; Antoniosi Filho, N.R. 2002. Estudo da estabilidade térmica de óleos e gorduras vegetais por TG/DTG e DTA. Eclética Química, 27: $10-14$.

Gerpen, J.V. 2005. Biodiesel processing and production. Fuel Processing Technology, 86: 1097-1107.

Holanda, A. 2004. Biodiesel e inclusão social, Cadernos de Altos Estudos. Disponível em www.camara.gov.br/conheca/ altosestudos/biodiesel. Acesso em 08/01/2008.

Knothe, G.; Gerpen, J.V.; Krahl, J.; Ramos, L.P. 2006. Manual do Biodiesel.Edgard Blucher, São Paulo, 340pp.

Ma, F.; Hanna, M.A. 1999. Biodiesel production: a review. Bioresource Technoogy, 70: 1-15.

Meher, L.C.; Sagar, D.V.; Naik, S.N. 2006. Technical aspects of biodiesel production by transesterification - A review. Renewable and Sustainable Energy Reviews, 10: 248-268.

Shay, E.G. 1993. Diesel fuel from vegetable-oils - status and opportunities. Biomass Bioenergy, 4: 227-242.

Shahid, E.M., Jamal, Y. 2008. A review of biodiesel as vehicular fuel. Renewable and Sustainable Energy Reviews, 12: 2484-2494.

Srivastava, A., Prasad, R. 2000. Triglycerides-based diesel fuels. Renewable and Sustainable Energy Reviews, 4: 111-133.

Recebido em 04/08/2008

Aceito em 28/10/2008 
